\title{
Prosodic Realization of Negation in Saisiyat and English
}

\author{
Wen-yu Chiang \& I Chang-Liao \\ National Taiwan University
}

\section{Introduction}

Cross-linguistically, negation may be realized by means of syntactic marking, prosodic marking or a combination of the two, depending on the prosodic characteristics of the language in question. Syntactically, a language can use a single negator to express negation; such as not in English, or use various negators for different syntactic structures, such as those in Austronesian languages of Taiwan. Negation can also be marked prosodically. For example, Yaeger-Dror (2002) found that the $\mathrm{F}_{0}$ (fundamental frequency) of English not and French pas are higher than surrounding words. The current literature suggests that such prosodic differences accompanying the syntactic marking of negation are relatively common; the use of only prosodic marking to realize negation, in contrast, is relatively rare.

The question of whether a negator is invariably acoustically more prominent than its surrounding words, however, remains unresolved. Semantically, negators bring new information to a sentence; for this reason, they assume 'focal prominence'. Yaeger-Dror (2002) proposes the 'Cognitive Prominence Principle', according to which cognitively prominent items, such as negators, should be prosodically marked. According to this principle, acoustic prominence enhances discourse participants' attention to focused items, which maximizes the effectiveness of communication.

Acoustic evidence for the 'Cognitive Prominence Principle' was found in Allen (1973). In this study, participants were required to utter a set of negative sentences. Measurement of f0 values within those sentences determined that the pitch of negators was usually higher than that of contiguous lexical items. According to Yager-Dror $(1985,2002)$, the unstable behavior of negators stems from the conflict between the 'Cognitive Prominence Principle' and what they have termed the 'Social Agreement Principle'. On the one hand, a negator, due to its sentential prominence, must be prosodically marked in order to comply with the Cognitive Prominence Principle. On the other hand, the Social Agreement Principle discourages emphasis on any objection to a conversation partner's previous assertion, which would effectively eliminate any prosodic prominence assigned to negators. Yager-Dror's research suggests that the choice to assign prosodic prominence to negators may be sensitive to the dynamics of culture and discourse.

Whether the prosodic prominence on negators found in English negative sentences can be found across a range of language types has yet to be explored.

The current study focuses on the prosodic realization of negators in Saisiyat ${ }^{1}$, an endangered aboriginal language of Taiwan, and compares its prosodic realization of negation with that of English. The results of this study indicate that sentential subjects are the most acoustically prominent items in the Saisiyat negative sentences measured. This contrasts sharply with the English experimental sentences, in which the negator itself was the most acoustically prominent item. These findings suggest that Saisiyat is a pitch-accent language; thus, the presence of negators does not significantly change the prosodic 
parameters of surrounding words. English, in contrast, is an intonation language, so the presence of negation results in substantial prosodic modification. This suggests that the phenomenon of negation is universally prominent; however, languages with different prosodic systems will adopt different strategies for realizing prominence.

\section{The structure of Saisiyat}

This section will provide a brief introduction to the phonology, morphology and syntax of Saisiyat. This information was collected from three sources: Yeh (2000), our own fieldwork and a database of Saisiyat discourse collected at the Graduate Institute of Linguistics of National Taiwan University.

\subsection{The phonemic inventory of Saisiyat}

The phonemic inventory of Saisiyat consists of seventeen consonants and six vowels; these appear in the tables below:

Table 1 Consonants in Saisiyat ${ }^{2}$

\begin{tabular}{|c|c|c|c|c|c|c|}
\hline & & Bilabial & Alveolar & Palatal & Velar & Glottal \\
\hline Stop & & $\mathrm{P}$ & $\mathrm{T}$ & & $\mathrm{K}$ & $2(0)$ \\
\hline Nasal & & $\mathrm{M}$ & $\mathrm{N}$ & & $\eta(\mathrm{ng})$ & \\
\hline Fricative & Voiceless & & S & $\int(S)$ & & $\mathrm{h}$ \\
\hline & Voiced & & $\mathrm{Z}$ & & & \\
\hline Lateral & & & $L$ & l(L) & & \\
\hline Thrill & & & & $\mathrm{R}$ & & \\
\hline Glide & & $\mathrm{W}$ & & $j(y)$ & & \\
\hline
\end{tabular}

Table 2 Vowels in Saisiyat

\begin{tabular}{|c|c|c|c|}
\hline & Front & Central & Back \\
\hline High & I & & \\
\hline Mid & $\propto(\mathrm{oe})$ & $\partial(\mathrm{e})$ & 0 \\
\hline Low & $æ(\mathrm{ae})$ & $\mathrm{A}$ & \\
\hline
\end{tabular}

Pitch accent within words usually falls on the last syllable, except for function words and place names. The most prevalent syllable structure is CV and CVC (Chiang and Chiang, 2004).

\subsection{Saisiyat case marking}

In contrast with other Austronesian languages of Taiwan, which exhibit VOS word order, Saisiyat has SVO word order. Case markers usually occur before nouns to mark their syntactic function. According to Yeh (2000), there are six case markers in Saisiyat, each of which is divided into two categories: persons (not including pronouns) and common nouns, as shown in Table 3: 
Table 3: The Case System of Saisiyat (Yeh, 2000)

\begin{tabular}{|l|c|c|c|c|c|c|}
\hline \multicolumn{1}{|c|}{} & $\begin{array}{c}\text { Nominative } \\
\text { case }\end{array}$ & $\begin{array}{c}\text { Accusative } \\
\text { case }\end{array}$ & $\begin{array}{c}\text { Genitive } \\
\text { case }\end{array}$ & $\begin{array}{c}\text { Possessive } \\
\text { case }\end{array}$ & $\begin{array}{c}\text { Dative } \\
\text { case }\end{array}$ & $\begin{array}{c}\text { Locative } \\
\text { case }\end{array}$ \\
\hline Persons & $\begin{array}{c}q \\
\text { hi }\end{array}$ & $\mathrm{Hi}$ & $\mathrm{Ni}$ & Pan-a & 2ini & $\begin{array}{c}\text { Kan } \\
\text { Kala }\end{array}$ \\
\hline $\begin{array}{l}\text { Common } \\
\text { nouns }\end{array}$ & $\begin{array}{c}\varnothing \\
\mathrm{ka}\end{array}$ & $\mathrm{Ka}$ & $\begin{array}{c}\text { noka } \\
\text { no }\end{array}$ & Pan noka-a & No & Ray \\
\hline
\end{tabular}

\subsection{Saisiyat focus markers}

Like other Austronesian languages, Saisiyat uses focus markers to highlight the focused constituent in a sentence. Yeh (2000) divided these into two groups and four different kinds of focus markers within those groups, classified according to the relationship between the verb and the semantic role of the arguments. Focus is morphologically affixed to the verb, and any constituent can receive Focus: an agent, a patient or a location, among other arguments. This is illustrated in Table 4:

Table 4: The Focus Maker System In Saisiyat (Yeh, 2000)

\begin{tabular}{|l|c|c|}
\hline Focus markers & Group I & Group II \\
\hline Agent focus (AF) & $\mathrm{m}-,-$ om-, $\mathrm{ma}-, \phi$ & $\Psi$ \\
\hline Patient focus (PF) & - -n & -1 \\
\hline Locative focus (LF) & -an & \\
\hline Referential focus (RF) & si- & -ani \\
\hline
\end{tabular}

The choice between Group I and Group II focus markers is determined by negator type, which will be explained in section 2.4. Examples (1) through (4) illustrate the use of different types of focus markers in positive sentences.

\section{$<$ Example of AF>}

(1) $₫$ ?oja? $\int$-om- $\beta$ t ka korkorin

Nom mother AF-beat Acc child

"Mother beats the child" (data from our field work)

\section{<Example of PF>}

(2) korkorin noka ?oja? Səßət-en

child Gen mother beat-PF

"The child is beaten by mother." (data from our field work)

\section{<Example of LF>}

(3) ahœ' k-om-ita ka takəm ray katis-ralom-an dog see-AF Acc frog Loc KATIS-water-LF

"The dog was looking at a frog inside a container." (data from Frog Story $7^{3}$, IU $1-3)$

\section{<Example of RF>}

(4) kahœj si-səßət ni ßaki? ka korkorin

stick RF-beat Gen grandfather Acc child

"The grandfather uses a stick to beat the child" (data from Yeh, 2000) 
In (1), adding the AF infix -om- to the verb $\int \partial \beta \partial t$ 'beat' marks focus on the agent Poja ? 'mother', which creates a sentence similar in meaning to the English active voice, hence 'Mother beats the child'. When the verb takes the PF suffix $-\partial$ in (2), the patient becomes the focus of the sentence, which creates a meaning similar to the English passive voice, hence 'The child is beaten by mother'. In (3), the LF suffix -an is added to the noun ralom 'water', creating the inflected word katisraloman 'container', which is perceived as sentential focus on the location of the water. In (4), the use of the RF (referential) suffix places narrow focus the instrument kah aj 'stick'.

The range of pragmatic uses for focus markers in Saisiyat is actually much more complex than the examples illustrated above would suggest, and an exhaustive discussion of them is beyond the scope of this paper. Thus, we limit our current discussion of focus to the hypothesis that Saisiyat's ability to mark focus syntactically allows it to minimize reliance on prosodic cues for marking focal prominence. Since focus is marked using inflectional morphology, the word undergoes minimal changes from the lexical to the postlexical level in Saisiyat. Thus, the intonational pattern of Saisiyat remains relatively stable and predictable, like that of other pitch accent languages such as Japanese. In addition, since negators marked even more specifically by being matched with one of eight different focus markers in Saisiyat, we expect the negator and its surrounding words to undergo fewer prosodic changes than those in English do.

\subsection{Negators in Saisiyat}

Saisiyat has an inventory of eight negators: Pokik, Pokaj, Pamkik, Pamkaj, kayni?, Poka?, Rizi? and Pin Pini? (Yeh, 1998, 2000). Negators are chosen from this inventory according to the syntactic constructions in which they appear, and they are followed by verbs with focus markers chosen according to sentential focus. Table 5 provides glosses, distributions and co-occurrence restrictions of negators in Saisiyat.

Table 5: Negators in Saisiyat ${ }^{4}$

\begin{tabular}{|c|c|c|c|c|}
\hline Negator & Translation & Construction & $\begin{array}{l}\text { Co-occurrence } \\
\text { restrictions }\end{array}$ & Focus marker \\
\hline Pokik & Not & & $\begin{array}{l}\text { Nouns } \\
\text { [+stative]verbs } \\
\text { verbs with } \\
\text { aspect markers }\end{array}$ & \\
\hline Pokaj & Not & & [-stative]verbs & Group II \\
\hline Pamkik & will not & \multicolumn{3}{|c|}{ The same as ?okik } \\
\hline Pamkaj & will not & \multicolumn{3}{|c|}{ The same as Rokay } \\
\hline Kajni? & not want (to) & Volitional & $\begin{array}{l}\text { nouns } \\
\text { verbs }\end{array}$ & Group I \\
\hline Poka? & There is not & Existential & Nouns & \\
\hline Rizi? & Don't... & Imperative & Verbs & Group I \\
\hline Rin Rni? & not yet & & $\begin{array}{l}\text { verbs } \\
\text { adverbs }\end{array}$ & Group II \\
\hline
\end{tabular}




\section{Experiment 1: Saisiyat expression of prosodic prominence in negative sentences}

First, we investigated the relative prosodic prominence of negators in Saisiyat and compared them to those occurring in English negative sentences. Allen's (1973) investigation of English negative sentences demonstrated that negative modals are prosodically prominent, specifically by being produced with raised pitch. The current experiment tested this observation on Saisiyat negative sentences, as well as on a set of English sentences, in order to confirm Allen's findings.

\subsubsection{Methodology}

The Saisiyat materials designed for this experiment consisted of 15 negative sentences, an example of which is given in (5). ${ }^{5}$

\section{<Saisiyat sentence >}

\section{(5) ?œßaj ?okik minatini?}

?œßaj Neg brother

"?œßaj is not a brother"

Each negative sentence contains a single subject, negator and a predicate. The predicate consists of either a noun or a stative/dynamic verb, depending on the negator chosen. The grammatical subject of each sentence was $2 \propto \beta a j$, a common male name. All types of negator were included in the sentences except for Rin Zini? 'not yet', because its relatively complex syntactic structure would have made the sentence in which it appeared differ substantially from the other experimental items. Words appearing after negators were controlled for segmental content; these were limited to words composed exclusively of sonorants and vowels, so that an uninterrupted pitch track could be extracted from that area. Our Northern Saisiyat informant confirmed that all experimental sentences were grammatical and acceptable. English sentences used in the study were direct translations of the Saisiyat sentences. In all cases, the sentential subject was the English male name "Bob". An example is given in (6):

\section{<English sentences>}

\section{(6) Bob is not my brother.}

Three informants participated in the experiment: two native Saisiyat informants and one native British English informant. One of the Saisiyat informants speaks Northern Saisiyat and the other speaks Southern Saisiyat". Both are male, and between 50-60 years of age. They also speak Japanese and Hakka, a Chinese dialect spoken in Taiwan. The British English-speaking informant is a 24-year-old male. By self-report, none of the informants had a problem related to either hearing or articulation.

Recordings were made in the speech lab at the Graduate Institute of Linguistics at National Taiwan University, using a Kay Elemetrics CSL 4400. A condenser microphone was placed approximately 10 centimeters away from the informants' mouths for the duration of the recording. Total recording time for each participant was approximately one hour.

Saisiyat is a language without a writing system, so it was not possible to 
elicit the negative sentences using written materials. Instead, informants were asked questions by the researcher, and instructed to answer each of the questions in the negative, an example of which is given in (7).

\section{<Elicitation of negative sentences>}

(7) Researcher: Tœßaj Tokik minatini? ay?

(Is not ?œßaj a brother?)

Informant: $\quad$ Pœßaj Tokik minatini?.

(?œßaj is not a brother.)

After all recordings had been completed, Praat 4.1.19 signal processing software was used to measure the pitch, amplitude and duration of the vowels and coda consonants appearing in stressed syllables which, in the Saisiyat materials, were invariably final syllables. Syllable onsets were excluded from these measurements to avoid the confound of microprosodic variation that would have been introduced by different initial consonants. For the same reason, the accusative marker $k a$, which occurs in existential sentences, was also excluded from measurement.

\subsubsection{Results}

Table 6 below summarizes comparison among the informants of Northern Saisiyat, Southern Saisiyat, and English with respect to the parameters of both pitch and intensity peaks. The letter $X$ represents the word following the negator in any given sentence.

Table 6 Differences between Subject, negator, and X with respect to pitch peak and intensity peak for three informants

\begin{tabular}{|c|c|c|c|c|c|c|}
\hline & & & Subject & Negator & $\mathrm{X}$ & ANOVA \\
\hline Northern & Pitch Peak & $\begin{array}{l}\text { Mean } \\
\text { SD }\end{array}$ & $\begin{array}{r}134.89 \\
8.17\end{array}$ & $\begin{array}{l}127.1 \\
12.29\end{array}$ & $\begin{array}{r}121.29 \\
8.39\end{array}$ & $F(2,42)=7.27, p<.01$ \\
\hline Saisiyat & Intensity Peak & $\begin{array}{l}\text { Mean } \\
\text { SD }\end{array}$ & $\begin{array}{r}78.43 \\
2.69\end{array}$ & $\begin{array}{r}75.35 \\
2.34\end{array}$ & $\begin{array}{r}75.12 \\
1.64\end{array}$ & $\begin{array}{c}F(2,42)=9.986, \\
p<.01\end{array}$ \\
\hline Southern & Pitch Peak & $\begin{array}{l}\text { Mean } \\
\text { SD }\end{array}$ & $\begin{array}{r}115.73 \\
7.08\end{array}$ & $\begin{array}{r}107.21 \\
7.23\end{array}$ & $\begin{array}{r}100.43 \\
10.23\end{array}$ & $\begin{array}{c}F(2,42)=12.772, \\
p<.01\end{array}$ \\
\hline Saisiyat & Intensity Peak & $\begin{array}{l}\text { Mean } \\
\text { SD }\end{array}$ & $\begin{array}{l}76.4 \\
3.61\end{array}$ & $\begin{array}{r}72.35 \\
4.44\end{array}$ & $\begin{array}{r}70.83 \\
4.09\end{array}$ & $\begin{array}{c}F(2,42)=7.551, \\
p<.01\end{array}$ \\
\hline \multirow{2}{*}{ English } & Pitch Peak & $\begin{array}{l}\text { Mean } \\
\text { SD }\end{array}$ & $\begin{array}{r}130.77 \\
4.67\end{array}$ & $\begin{array}{r}142.73 \\
5.17\end{array}$ & $\begin{array}{r}110.69 \\
6.89\end{array}$ & $\begin{array}{c}F(2,42)=122.816 \\
p<.01\end{array}$ \\
\hline & Intensity Peak & Mean & 77.24 & 72.63 & 68.5 & $\begin{array}{c}F(2,42)=46.147 \\
p<.01\end{array}$ \\
\hline
\end{tabular}

Table 6 shows that among subject, negator and $X$, both pitch peak and intensity peak (taken to be indicators of prominence) are realized on the sentential subject for the Northern Saisyat informant. The mean difference between item categories was found to be significant in a one-way ANOVA $(F(2,42)=7.27$, $\mathrm{p}<.01$ for pitch peak, and $\mathrm{F}(2,42)=9.986, \mathrm{p}<.01$ for intensity peak). A post-hoc 
test indicated that the difference between $P \propto \beta a j$ and $\mathrm{X}$ contributes to the contrast in pitch peak mean, while the contrast in intensity peak mean is created by $? \propto \beta a j$ being significantly higher than both $? \propto \beta a j$ and $\mathrm{X}$.

The Southern Saisiyat informant's data displays patterns similar to those of the Northern Saisiyat informant; both pitch and intensity peaks are realized on the sentential subject $(F(2,42)=12.772$, $p<.01$ for pitch peak and $F(2,42)=7.551$, $\mathrm{p}<.01$ for intensity peak). A post-hoc test revealed that the significant difference emerges as the result of differences between item types, i.e. the subject and negator, and between the subject and $X$.

The English informant's data with respect to intensity peak does not differ significantly from Saisiyat informants' data; the highest mean of peak intensity occurs at the sentential subject $(F(2,42)=46.147, p<.01)$. However, the English informant's data does differ with respect to peak f0. In the English data, the highest pitch peaks were realized on negators $(F(2,42)=122.816, p<.01)$. This result confirms Allen (1973), in which pitch peaks were realized most often on negators in English. A post-hoc test showed that the mean differences of pitch and intensity peak among the three item types are all significant.

\subsection{Experiment 2: -aj sentences}

The results of Experiment 1 suggest that sentential subjects represent the most acoustically prominent constituents in Saisiyat negative sentences. To investigate the possibility that microprosodic effects of the 'aj' coda in the $b a j$ subject have skewed the results of Experiment 1, another 15 pairs of sentences were constructed, each word of which has an -ay coda, an example of which appears in (6) ${ }^{7}$. If we obtain similar results holding vowel quality constant across item types, it diminishes the likelihood that /aj/ is simply intrinsically higher in pitch and/or amplitude than other vowels.

\subsubsection{Results}

As can be seen in table 7, $2 \propto \beta a j$ still remains the most prominent item, even when the last three items have all been controlled for vowel quality.

Table 7: Differences between subject, negator, and $X$ with respect to pitch peak and intensity peak for the three informants (three item codas controlled as -ay)

\begin{tabular}{|c|c|c|c|c|c|c|}
\hline & & & Subject & Negator & $\bar{X}$ & ANOVA \\
\hline \multirow{4}{*}{$\begin{array}{c}\text { Northern } \\
\text { Saisiyat }\end{array}$} & \multirow{2}{*}{ Pitch Peak } & Mean & 134.99 & 118.16 & 111.2 & $F(2,42)=25.496$ \\
\hline & & $\mathrm{SD}$ & 9.57 & 11.95 & 5.45 & $\mathrm{p}<.01$ \\
\hline & \multirow{2}{*}{ Intensity Peak } & Mean & 65.94 & 63.34 & 63.05 & $F(2,42)=12.185$ \\
\hline & & SD & 1.27 & 1.39 & 2.41 & $p<.01$ \\
\hline \multirow{4}{*}{$\begin{array}{l}\text { Southern } \\
\text { Saisiyat }\end{array}$} & \multirow{2}{*}{ Pitch Peak } & Mean & 136.93 & 121.49 & 122.49 & $F(2,42)=23.081$ \\
\hline & & $\mathrm{SD}$ & 4.71 & 7.2 & 8.45 & $P<.01$ \\
\hline & \multirow{2}{*}{ Intensity Peak } & Mean & 71.69 & 67.95 & 69.37 & $F(2,42)=15.812$, \\
\hline & & SD & 1.51 & 1.46 & 2.4 & $p<.01$ \\
\hline
\end{tabular}

A post-hoc test showed that the significance of both pitch and intensity peaks stems from the mean difference between $2 \propto \beta a j$ and $2 o k a j, 2 \alpha \beta a j$ and $\mathrm{X}$-ay. That is, the pitch and intensity peak of $2 \alpha \beta a j$ is significantly higher than Pokaj and X-ay. 
The Southern Saisiyat informant's data are similar to those of the Northern Saisiyat informant. The most prominent item is still the subject $P a \beta a j$ in terms of both pitch and intensity peaks. In addition, a post-hoc test revealed that the subject $P \propto \beta a j$ is significantly higher than both $P o k a j$ and $\mathrm{X}$-ay.

\subsection{Experiment 3: Sentences starting with ? al Palak 'young person'}

The results of Experiments 1 and 2 support our conclusion that the subject is the most acoustically prominent item in Saisiyat negative sentences. To strengthen this conclusion, we constructed another set of sentences, the aim of which was to decrease the acoustic prominence of the sentential subject by using the word Pal Palak 'young person', which ends with a voiceless stop consonant ' $k$ ', rather than any open syllable. If we obtain similar results after deliberately decreasing the acoustic prominence of the subject by choosing a syllable composed of segments that are intrinsically lower in fo and amplitude, then our conclusion will be reinforced. In Experiment 3, the negator and " $X$ " consisted of the same items that appeared in Experiment 2. An example is given below in (8).

(8) PalPalak Pokaj ß@aj

young_person Neg give

'The young person does not give'

\subsubsection{Results}

Table 8 shows that there is no significant difference from the previous experiments in terms of pitch peak location. Subject ?al?alak was shown to be the location of pitch peak in a one-way ANOVA.

Table 8: Differences between Subject (with ak coda), negator, and X with respect to pitch peak and intensity peak for the three informants

\begin{tabular}{|c|c|c|c|c|c|c|}
\hline & & & Subject & Negator & $\mathbf{X}$ & ANOVA \\
\hline \multirow{4}{*}{$\begin{array}{l}\text { Northern } \\
\text { Saisiyat }\end{array}$} & \multirow{2}{*}{ Pitch Peak } & Mean & 124.47 & 108.01 & 100.92 & $F(2,42)=20.25$, \\
\hline & & $\mathrm{SD}$ & 8.15 & 7.41 & 7.08 & $\mathrm{p}<.01$ \\
\hline & \multirow{2}{*}{ Intensity Peak } & Mean & 62.31 & 61.32 & 61.81 & $F(2,42)=1.074$ \\
\hline & & SD & 1.76 & 1.68 & 2.09 & $p>.01$ \\
\hline \multirow{4}{*}{$\begin{array}{c}\text { Southern } \\
\text { Saisiyat }\end{array}$} & \multirow{2}{*}{ Pitch Peak } & Mean & 119.39 & 114.29 & 110.93 & $F(2,42)=6.125$, \\
\hline & & SD & 7.05 & 5.89 & 7 & $p<.01$ \\
\hline & \multirow{2}{*}{ Intensity Peak } & Mean & 57.09 & 60.04 & \multirow{2}{*}{\multicolumn{2}{|c|}{$\begin{array}{l}59.6 \\
3.36\end{array} \mathrm{~F}(2,42)=.491, \mathrm{p}>.01$}} \\
\hline & & $\mathrm{SD}$ & 14.81 & 1.32 & & \\
\hline
\end{tabular}

However, in these sentences, the subject is no longer the location of peak intensity, and there is no significant difference among the three item types $(F(2,42)=.491, p>.01)$. A post-hoc test showed that the mean pitch peak of Pal Palak is significantly higher than those of Pokaj and X-ay. It should be noted that in this experiment, the two Saisiyat speakers both realized pitch peak on the sentential subject, but differed in their placement of the intensity peak. The Southern Saisyat informant realized the intensity peak on the negator, while the Northern speaker's intensity peak remained on the sentential subject. Results of a one-way ANOVA indicate that the three item types are significantly different with respect to mean pitch peak. In contrast, there is no significant difference 
among the mean intensity peaks of the three items. The mean intensity peak of the subject Pal Palak is even a little lower than other two items, which is quite different from the results from previous experiments.

From the analysis of the post-hoc test, the mean pitch peak is significantly higher than that of $\mathrm{X}$-ay. There is no significant difference between the mean pitch peaks of Pal?alak and Pokaj.

\subsection{Summary and conclustion}

The English informant's data from Experiment 1 confirm Allen (1973), in the sense that negators were the most prominent items (as measured by peak $\mathrm{f} 0$ and intensity) in English negative sentences. However, this phenomenon is absent in Saisiyat negative sentences; the most prominent item in these sentences are the sentential subjects.

To further test the acoustic prominence of Saisiyat sentential subjects, we designed Experiment 2, in which the coda of each item was held constant as /aj/; still, sentential subjects remained the most prominent item. Experiment 3 decreased the sonority of the subject by changing it to a closed syllable with a voiceless stop coda. Under those conditions, sentential subjects remained the locus of pitch peak, but not uniformly of peak intensity. The results of Experiments 1, 2 and 3 provide strong evidence for the claim that the most acoustically prominent item in Saisiyat negative sentences is the sentential subject.

In addition, a disjunction between mean pitch peak and intensity peak can be seen in the English data in Experiment 1 and in the Saisiyat data in Experiment 3. In Experiment 1, the mean pitch peak falls on English negators, but the mean intensity peak falls on sentential subjects. In Experiment 3, we can see that the subject remains the locus of the mean pitch peak, but not peak intensity.

Since the post-hoc test in Experiment 1 showed that there are significant differences among all three item types in English negative sentences, we suggest that there is a principled difference in prominence ranking orders between English and Saisyat negative sentences. The ranking order for English would be negator $>$ subject $>X$. and for Saisiyat, subject $>$ negator $>X$.

The different prosodic characteristics of Saisiyat and English suggest that a variety of intonational strategies is available for the linguistic realization of negation. For example, negators are cognitively prominent, but they are not necessarily the most acoustically prominent items in a negative sentence. Thus, the Cognitive Prominence Principle can be applied to English negators but not to those in Saisiyat. In fact, Saisiyat informants realize more acoustic prominence on sentential subjects than on any other items in a negative sentence. Moreover, in English negative sentences, various prosodic changes are realized on the " $X$ " constituent, which was not found in the data of Saisiyat informants.

In interpreting our results, it must be noted that unlike Yager-Dror (1985, 2002), the current study does not take pragmatic factors into consideration; the materials used in this study are designed sentences rather than natural discourses, and the recording procedure is strictly controlled.

Finally, the question of why Saisiyat realizes acoustic prominence on sentential subjects rather than negators is not yet clear. A possible explanation is that the prosodic focus in Saisiyat sentences is positionally determined; i.e. the focus falls on the agent as a default strategy. It must also be noted that the 
materials in this study were restricted to agent-focused sentences, so it has yet to be determined whether focus in different positions would receive the same sentential prominence. Further studies are needed to test if agents are always the intonational focus in Saisiyat.

This paper provides a typological comparison of the prosodic realization of negation in Saisiyat and English and provides preliminary evidence that Saisiyat is best classified as a pitch-accent language. Future study should examine the cue-trading relationships of morphosyntax and prosody in the realization of negation as it occurs in natural discourse, across a wide variety of language types.

\section{Endnotes}

ACKNOWLEDGMENT: This study was sponsored by NSC 92-2411-H002-079. The authors would like to extend our great gratitude to the three informants, Paway a Tahis, Oebay a Oemaw, and Terry for their helpful data and enthusiasm. We are also grateful to the other two members in NSC Saisiyat Intonation Project, Fang-mei Chiang and Hung-chun Tung, for their valuable suggestions and discussions of this work. Special thanks go to Tanya Viger for her insightful comments on the content of this paper.

1. Saisiyat is an endangered language in Taiwan with about 7000 speakers. It belongs to the Austronesian language family and has two dialectal variations--North Saisiyat (Daai dialect) and South Saisiyat (Tungho dialect). North Saisiyat is spoken in Miao-Li and South Saisiyat is spoken in Xin-Zhu. The speaker population of these two dialects of Saisiyat lives in central Taiwan.

2. The alphabets in parentheses represent the ASCII equivalent of the original IPA form, which is the transcription system that appears in Yeh (2000). For consistency, all the Saisiyat words appearing subsequently in our study will be transcribed in standard IPA.

3. Frog Story is one of the texts collected in a research project of Saisiyat in National Taiwan University. Project No.: NSC 91-2411-H-002-088

4. The materials used in this study include all negators in the table above, except for Pamkik and Pamkay. These two are actually negators blended with future tense marker Pam (Yeh, 2000)

5. A complete list of the experimental sentences appears in Appendix A

6. Since Saisiyat is an endangered language, informants who are both proficient enough to participate in the experiment and fluent enough in Mandarin Chinese to comprehend the instructions are very difficult to find.

7. A complete list of sentences is given in Appendix B. 
Appendix A: Designed Saisiyat and English sentences used in experiment 1

\begin{tabular}{|c|c|c|}
\hline No. & Saisiyat & English \\
\hline \multirow{2}{*}{1} & 'oebay minatini' & Bob is my brother \\
\hline & 'oebay 'okik minatini' & Bob is not my brother \\
\hline \multirow{2}{*}{2} & 'oebay lalaor & Bob dozes \\
\hline & 'oebay 'okik lalaor & Bob does not doze \\
\hline \multirow{2}{*}{3} & 'oebay liyabo' & Bob is rich \\
\hline & 'oebay 'okik liyabo' & Bob is not rich \\
\hline \multirow{2}{*}{4} & 'oebay m-atol & Bob sings \\
\hline & 'oebay haSa'm-atol & Bob does not sing \\
\hline \multirow{2}{*}{5} & 'oebay miltamako' & Bob hunts \\
\hline & 'oebay haSa' miltamako' & Bob does not hunt \\
\hline \multirow{2}{*}{6} & 'oebay laloehay & Bob has fun \\
\hline & 'oebay haSa' laloehay & Bob does not have fun \\
\hline \multirow{2}{*}{7} & 'oebay mayna:a' & Bob waits \\
\hline & 'oebay 'okay ayna:a' & Bob does not wait \\
\hline \multirow{2}{*}{8} & 'oebay mwa:i' & Bob comes to my place \\
\hline & 'oebay 'okay wa:i' & Bob does not come to my place \\
\hline \multirow{2}{*}{9} & "oebay miltamako" & Bob smokes \\
\hline & "oebay okay miltamako' & Bob does not smoke \\
\hline \multirow{2}{*}{10} & 'oebay hayza' ka lapowar & Bob has a guava \\
\hline & 'oebay 'oka' ka lapowar & Bob does not have a guava \\
\hline \multirow[b]{2}{*}{11} & 'oebay hayza' ka laro' & Bob has a persimmon \\
\hline & 'oebay 'oka' ka laro' & $\begin{array}{l}\text { Bob does not have a } \\
\text { persimmon }\end{array}$ \\
\hline \multirow{2}{*}{12} & 'oebay hayza' ka mona: & Bob has a snail \\
\hline & 'oebay 'oka' ka mona: & Bob does not have a snail \\
\hline \multirow{2}{*}{13} & 'oebay'am lapowar & Bob wants a guava \\
\hline & 'oebay kayni' lapowar & Bob does not want a guava \\
\hline \multirow[b]{2}{*}{14} & 'oebay 'am laro' & Bob wants a persimmon \\
\hline & 'oebay kayni' laro' & $\begin{array}{l}\text { Bob does not want a } \\
\text { persimmon }\end{array}$ \\
\hline \multirow{2}{*}{15} & 'oebay 'am mona: & Bob wants a snail \\
\hline & 'oebay kayni' mona: & Bob does not want a snail \\
\hline
\end{tabular}


Appendix B: Designed Saisiyat sentences used in experiment 2

\begin{tabular}{|c|c|}
\hline No. & Saisiyat \\
\hline \multirow{2}{*}{1} & 'oebay m-obay \\
\hline & 'oebay'okay be:ay \\
\hline \multirow{2}{*}{2} & 'oebay ma-sangay \\
\hline & 'oebay 'okay sangay \\
\hline \multirow{2}{*}{3} & "oebay romamramay \\
\hline & 'oebay 'okay ramramay \\
\hline \multirow{2}{*}{4} & 'oebay so-mo-way \\
\hline & 'oebay 'okay soway \\
\hline \multirow{2}{*}{5} & 'oebay kipazay \\
\hline & 'oebay 'okay kipazay \\
\hline \multirow{2}{*}{6} & 'oebay kiboway \\
\hline & 'oebay 'okay kiboway \\
\hline \multirow{2}{*}{7} & 'oebay 'aelipoway \\
\hline & 'oebay 'okay 'aelipoway \\
\hline \multirow{2}{*}{8} & 'oebay inkonkonay \\
\hline & 'oebay 'okay inkonkonay \\
\hline \multirow{2}{*}{9} & 'oebay rasiwazay \\
\hline & 'oebay 'okay rasiwazay \\
\hline \multirow{2}{*}{10} & "oebay tisko-aewhay \\
\hline & 'oebay 'okay tisko-aewhay \\
\hline \multirow{2}{*}{11} & 'oebay masay \\
\hline & 'oebay 'okay pasay \\
\hline \multirow{2}{*}{12} & 'oebay omas'asay \\
\hline & 'oebay 'okay 'as'asay \\
\hline \multirow{2}{*}{13} & oebay maStalay \\
\hline & "oebay 'okay 'iStalay \\
\hline \multirow{2}{*}{14} & oebay min-balbalay \\
\hline & 'oebay 'okay balbalay \\
\hline \multirow{2}{*}{15} & 'oebay kakoway \\
\hline & 'oebay 'okay kakoway \\
\hline
\end{tabular}


Appendix C: Designed Saisiyat sentences used in experiment 3

\begin{tabular}{|c|c|}
\hline No. & Saisiyat \\
\hline \multirow{2}{*}{1} & 'al'alak m-obay \\
\hline & 'al'alak 'okay be:ay' \\
\hline \multirow{2}{*}{2} & 'al'alak ma-sangay \\
\hline & 'al'alak 'okay sangay \\
\hline \multirow{2}{*}{3} & 'al'alak romamramay \\
\hline & 'al'alak 'okay ramramay \\
\hline \multirow{2}{*}{4} & 'al'alak so-mo-way \\
\hline & "al'alak 'okay soway \\
\hline \multirow{2}{*}{5} & 'al'alak kipazay \\
\hline & 'al'alak 'okay kipazay \\
\hline \multirow{2}{*}{6} & 'al'alak kiboway \\
\hline & 'al'alak 'okay kiboway \\
\hline \multirow{2}{*}{7} & 'al'alak 'aelipoway \\
\hline & 'al'alak 'okay 'aelipoway \\
\hline \multirow{2}{*}{8} & 'al'alak inkonkonay \\
\hline & 'al'alak 'okay inkonkonay \\
\hline \multirow{2}{*}{9} & 'al'alak rasiwazay \\
\hline & 'al'alak 'okay rasiwazay \\
\hline \multirow{2}{*}{10} & "al'alak tisko-aewhay \\
\hline & 'al'alak 'okay tisko-aewhay \\
\hline \multirow{2}{*}{11} & 'al'alak masay \\
\hline & 'al'alak 'okay pasay \\
\hline \multirow{2}{*}{12} & 'al'alak omas'asay \\
\hline & 'al'alak 'okay 'as'asay \\
\hline \multirow{2}{*}{13} & 'al'alak maStalay \\
\hline & 'al'alak 'okay 'iStalay \\
\hline \multirow{2}{*}{14} & 'al'alak min-balbalay \\
\hline & 'al'alak 'okay balbalay \\
\hline \multirow{2}{*}{15} & 'al'alak kakoway \\
\hline & 'al'alak 'okay kakoway \\
\hline
\end{tabular}

\section{Reference}

Allen, J. (1973). Pitch peaks on negatives. Journal of the Acoustical Society of America, 55, S77 (Abstract)

Chiang, Wen-yu, \& Chiang, Fang-mei. (2004) The lexicon-level pitch accent in Saisiayt. Unpublished manuscript

Cruttenden, A. (1997). Intonation (2nd ed.). Cambridge: Cambridge University Press.

Yaeger-Dror, M. (2002). Register and prosodic variation, a cross language comparison. Journal of Pragmatics, 34, 1495-1536.

Yaeger-Dror, M.(1985). Intonational prominence on negatives in English. Language and Speech , 28, 197-230. 
Yeh, Marie M, Lilian M. Huang, Elizabeth Zeitoun, Anna H. Chang, Joy J. Wu. (1998).A Preliminary Study On Negative Constructions In Some Formosan Languages. Selected Papers From The Second International Symposium On Languages In Taiwan.(ISOLIT-II), 81 111

Yeh, Marie M葉美利, (2000). sai siya yu can kau yu fa [A Reference Grammar of Saisiyat]. Taipei: Yuan-Lio.

Wen-yu Chiang

Graduate Institute of Linguistics, National Taiwan University

No.1, Sec. 4, Roosevelt Road, Taipei, 106

Taiwan

wychiang@ntu.edu.tw

I Chang-Liao

Graduate Institute of Linguistics, National Taiwan University

No.1, Sec. 4, Roosevelt Road, Taipei, 106

Taiwan

r91142007@ntu.edu.tw 